\title{
The training effects of a continuing education program on nurses' knowledge and attitudes to palliative care: a cross sectional study
}

\section{Xian Chen}

Jiangsu Nursing Association

\section{Yuxi Zhang}

The First Affiliated Hospital of Nanjing Medical University

\section{Anne Arber}

The University of Surrey

\section{Xiaorong Huo}

Jiangsu Nursing Association

Jin Liu

The First Affiliated Hospital of Nanjing Medical University

\section{Cuihua Sun}

Jiangsu Nursing Association

\section{Ling Yuan}

The Affiliated Hospital of Nanjing University Medical School

\section{Xuemei Wang}

The First Affiliated Hospital of Nanjing Medical University

\section{Dan Wang}

The first affiliated Hospital of Xuzhou Medical University

\section{Jinfeng Wu}

The First Affiliated Hospital of Nanjing Medical University

Junjie Du ( $\nabla$ junjie.du@njmu.edu.cn )

The First Affiliated Hospital of Nanjing Medical University

\section{Research Article}

Keywords: attitude, knowledge, palliative care, continuing education

Posted Date: February 18th, 2022

DOI: https://doi.org/10.21203/rs.3.rs-1339271/v1 
License: (c) (i) This work is licensed under a Creative Commons Attribution 4.0 International License. Read Full License

Version of Record: A version of this preprint was published at BMC Palliative Care on April 26th, 2022. See the published version at https://doi.org/10.1186/s12904-022-00953-0. 


\section{Abstract}

Background: Most nurses in China have not been trained to take care of end-of-life patients appropriately due to lack of educational resources and insufficient training. A palliative care program was launched by the Jiangsu Nursing Association (JNA training program) and to identify gaps in palliative care training. The main aims of this study were to evaluate the training effects of the JNA training program on nurses' knowledge and attitudes to palliative care.

Methods: A cross-sectional study was conducted with 10048 registered nurses in all regions of Jiangsu. All participants completed an online questionnaire using the Chinese version of The Palliative Care Quiz for Nursing (PCQN-C) and the Frommelt Attitude Toward Care of the Dying scale (FATCOD-B-C). A propensity score matched analysis was performed between the nurses who had attended the JNA training program and whose who hadn't.

Results: The average score of PCQN-C among all nurses was 8.79, while the mean score of the FATCODB-C was 103.62. Those participants who attended the JNA training program had significantly better scores than those who did not. Propensity score matching analysis showed that the palliative care training program failed to improve nurses' knowledge in psychosocial and spiritual care or their attitudes towards the necessity of family support although there was positive impact on other aspects of palliative care.

Conclusions: Knowledge of palliative care among Chinese nurses remains low. Training programs may improve general knowledge and attitudes to palliative care. However, important aspects of knowledge such as communication skills, family support, and psychosocial aspects of care, are missing. These gaps should be filled in future palliative care training programs targeting nurses with oriental culture background.

\section{Background}

Palliative care aims to improve the quality of life for patients who have a serious or life-limiting disease (1). It is now widely accepted that palliative care is a core component of the role of all health professionals who care for dying patients (2). China is facing an unprecedented number of patients that require good quality palliative care because not only is China the most populous country in the world but also it has a rapid growth in the ageing population since entering the new century (3). However, according to the 2015 Quality of Death Index (4), comparing countries' hospitals and hospice environment, staffing numbers and skills, affordability of care, and quality of care, mainland China ranked 71 st out of 80 countries and regions.

This worrying concern about the quality of care of the dying in China aroused awareness and deep thinking of Chinese medical professionals as barriers that slowed the adoption of palliative care in China have been recognized (5-8). For instance, the shortage of professional palliative care staff, especially nurses who are the major caregiver to patients at the end of life, is severe. In China, most nurses have not 
been trained to take care of end-of-life patients appropriately due to lack of educational resources and insufficient training (9-11). A survey was conducted among 770 nurses from five Chinese provinces about their attitudes towards death and caring for the dying (12). Most nurses in the study did not have a positive attitude towards care of the dying, associated with their attitudes towards death as well as their cultural backgrounds and religious beliefs. Another qualitative study showed that oncology nurses in China encountered serious dilemmas when delivering end-of-life care and struggled to provide psychological care and a lack of communication skills were identified (13).

China has been trying to improve the situation through various measures. The National Health Commission of China issued a series of documents to provide policy and administrative supports for hospice and palliative care in $2016(14,15)$. A National Hospice Palliative Care Pilot Project has been launched since then which now takes in 29 provinces/municipalities covering 92 prefecture-level cities (15). As part of this strategy, Jiangsu Nursing Association (JNA) has launched a continuing education program on palliative care since 2019 (referred to as "JNA training program" in this paper) as the backbone for pilot hospice care sites and nursing homes all over the province (16).

There has not been enough data available to evaluate the educational effects of the training program, not to mention the fact that fundamental information about palliative care knowledge and practice among Chinese nurses is still missing (17). Therefore, this study compared Jiangsu nurses' knowledge of palliative care and attitudes towards end-of-life care between those who had been enrolled in the JNA training program and those who had not to evaluate its training effects and to identify gaps in the training program of this kind that need to fill in the future.

\section{Methods}

\section{Design and setting}

A descriptive cross-sectional design was used in this study. The study employed a mobile phone appbased survey containing a three-part questionnaire (Wenjuanxing, www.wjx.cn). The data collection period was from $8^{\text {th }}$ October to $22^{\text {nd }}$ October 2020 (i.e., within a period of two weeks). The ethical approval was obtained from JNA and the First affiliated hospital of Nanjing Medical University (approval number: 2016-SRFA-076). The research was presented according to the STROBE checklist for crosssectional research.

JNA distributed this anonymous, self-rated questionnaire to all nurses who attended the JNA training program in 2019 and other nursing members in Jiangsu via a WeChat applet and issued a notice to invite them to participate in the study. All study participants were provided with informed consent electronically prior to participating in the study. The informed consent page presented two options (Yes/No). Only subjects who chose "Yes" were guided to the questionnaire pages, and participants could quit the process at any time. 
All responses from the nurses who had attended the JNA training program 2019 were included in the study. In order to represent the situation of nurses proportionally in the whole province, a regionalstratified sampling method was applied for responses from nurses who did not attend the training program. Registered nurses located in 13 prefecture-level cities in Jiangsu province were divided into 13 regions based on their geographic locations while the online questionnaire was distributed to all regions. All valid answers of the questionnaire from one region were included in the study when there were less than 1,000 responses in that region, otherwise 1,000 valid answers were randomly selected in case there were more than 1,000 responses in that region.

\section{Instruments}

The online questionnaire consists of three parts: basic demographic and professional data, Chinese version of The Palliative Care Quiz for Nursing (PCQN-C), and Chinese version of the Frommelt Attitude Toward Care of the Dying scale (FATCOD-B-C).

\section{Demographic and professional data}

The first part of the questionnaire included participants demographics, nursing profession and their experience in palliative care. Demographic characteristic of nurses included gender, age, marital status, and personal beliefs. Nursing professional background included hospital classification, working years, level of nursing job, current working department, whether is an oncology nursing specialist, whether is a palliative care nursing specialist. Palliative care experience, and whether attended the JNA training program 2019.

\section{The Palliative Care Quiz for Nursing (PCQN) instrument}

The PCQN was originally designed by Ross et al (18), and was translated into Chinese and validated by Zou (19). The test-retest reliability was 0.782 and an internal consistency reliability of 0.758 . The PCQN consisted of 20 questions with three possible responses including true, false and do not know. The PCQN contained three categories: (1) philosophy and principles of palliative care; (2) pain and symptom management; and (3) psychosocial and spiritual care (20). The total score ranged from 0-20, the higher the score the better the knowledge of palliative care.

\section{The FATCOD-B-C instrument}

The FATCOD-B was first developed by Formmelt to test nurses' attitudes toward caring of the dying (21). It was modified and transferred into Chinese version (the FATCOD-B-C) by Wang to assess nurses' and nursing students' attitude towards caring for end-of-life patients in Mainland China (22). The FATCOD-B-C scale consisted of 29 items and it also classified into six subsets: Subset 1. attitude toward the interests of the dying person; Subset 2. attitude toward caring for the dying person; Subset 3. attitude toward the necessity of family support; Subset 4, attitude toward communication with the dying person; Subset 5 . attitude toward fear of caring of dying person; Subset 6 . attitude toward caring for the dying person's families. It reported the construct validity of FATCOD-B-C was acceptable with Cronbach's alpha 
coefficient 0.796 and the six subscales range form $0.610-0.863$. The score from the 29 questions were added together to calculate a total FATCOD-B-C score with a possible range from 29-145, with the higher scores indicating more positive attitudes.

Before data collection, a pilot study was conducted with 20 nurses from one local hospital to assess the clarity of the questionnaire and to evaluate the feasibility and clarity of the study. The questionnaire took on average 8 to 12 minutes to complete, and all the nurses in the pilot study found the questionnaire was clear and easy to understand. The data generated from the pilot study was not included in the data analysis.

Statistical analysis

To minimize confounding and selection biases, a propensity score matched analysis was performed between the nurses who attained the JNA training program 2019 and whose who did not. We estimated propensity scores using logistic regression modelling of baseline demographics and other covariates (hospital classification, working experience, level of nursing job, working department, oncology nursing specialist, palliative care nursing specialist, experience of caring for dying patients, and experience of discussing death with patients or their family members) which could have impact on the knowledge and attitude. We conducted propensity score-matching using 1:1 nearest neighbor matching without replacement with a caliper width of 0.1 . Covariate distributions between trained nurses and untrained nurses were balanced after conditioning on the propensity score (Supplementary table 3).

Data were analyzed using IBM SPSS Version 23.0. Descriptive analysis was used to describe the general data. For count data, frequencies and percentages were used. Comparisons between trained nurses versus untrained nurses were conducted in both the overall cohort as well as the propensity score matched subset by using independent samples t-test for continuous variables and the results were presented as mean difference with $95 \%$ confidence interval of the difference. P-value $<0.05$ indicated that a difference was statistically significant.

\section{Results}

A total of 10,048 nurses were recruited to the study as indicated in Fig. 1. The demographic characteristics of all participants are shown in Table 1. 
Table 1

Characteristics of the participants

\section{Characteristic}

\section{Demographics}

Gender

Male

Female

Age

$18-35$

$36-50$

$\geq 51$

Marital status

Single

Married

Divorced

Others

Personal beliefs

Christianity

Buddhism

Muslim

Others

None

Nursing profession

Hospital classification

Tertiary hospital
Total number (percentage, \%)

$221(2.10)$

$9827(97.90)$

7539 (75.03)

$2301(22.90)$

$208(2.07)$

$3056(30.41)$

$6678(66.46)$

$157(1.56)$

$157(1.56)$

199 (1.98)

$506(5.04)$

$10(0.10)$

$18(0.18)$

$9315(92.70)$

Abbreviations: ICU, Intensive care unit. JNA, Jiangsu Nursing Association.

${ }^{a}$ A dying patient was defined in the present study as a patient with life-limiting illness and his/her life expectancy is 6 months or less.

bThis experience was defined as having discussed any topics of death with patients or with their family members. 


\section{Characteristic}

Secondary hospital

Primary hospital/Surgery

Working years

$\leq 5$

$6-10$

$11-15$

$16-20$

$\geq 21$

Level of nursing job

Junior level

Medium level

Senior level

Working department

Department of oncology

Department of geriatrics

Other departments of internal medicine

Departments dealing with surgeries

Pediatrics

ICU or Emergency department

Outpatient department

Oncology nursing specialist

Yes

No

\section{Total number (percentage, \%)}

2924 (29.10)

$264(2.63)$

3356 (33.40)

2964 (29.50)

1554 (15.47)

858 (8.54)

$1316(13.10)$

$6320(62.90)$

2819 (28.06)

909 (9.05)

1161 (11.55)

429 (4.26)

3393 (33.76)

2908 (28.94)

434 (4.31)

1205 (11.99)

$518(5.15)$

147 (1.46)

9901 (98.54)

Palliative care nursing specialist

Abbreviations: ICU, Intensive care unit. JNA, Jiangsu Nursing Association.

${ }^{a} A$ dying patient was defined in the present study as a patient with life-limiting illness and his/her life expectancy is 6 months or less.

bThis experience was defined as having discussed any topics of death with patients or with their family members. 


\section{Characteristic}

Yes

No

\section{Experience in palliative care}

Experience of caring for dying patients ${ }^{a}$

$\begin{array}{ll}\text { Yes } & 5256(52.31) \\ \text { No } & 4792(47.69) \\ \text { Yes } & 4074(40.56) \\ \text { No } & 5974(59.46) \\ \text { Attended the JNA training program 2019 } & \\ \text { Yes } & 1686(16.78) \\ \text { No } & 8362(83.22)\end{array}$

Abbreviations: ICU, Intensive care unit. JNA, Jiangsu Nursing Association.

${ }^{a}$ A dying patient was defined in the present study as a patient with life-limiting illness and his/her life expectancy is 6 months or less.

bThis experience was defined as having discussed any topics of death with patients or with their family members.

\section{Knowledge Of Nurses About Palliative Care}

The mean knowledge of palliative care score was 8.79 (range $0-17, S D=2.79$ ) (Table 2). The distribution of nurses' knowledge about palliative care on the PCQN scale was shown in Supplementary table 1 . The mean knowledge for philosophy and principle of palliative care score was poor with 1.21 (range 0-4, SD $=0.96$ ). The nurses' knowledge regarding psychosocial and spiritual care in this study was poor with the mean score 0.5 (range $0-3, S D=0.67$ ). The nurses demonstrated better knowledge regarding pain and symptom control. The mean score was 7.08 (range $0-13, \mathrm{SD}=2.21$ ). 
Table 2

The knowledge of palliative care and attitudes toward care of the dying among all nurses

\section{Questionnaires}

Total PCQN score ${ }^{\mathrm{a}}$

Category 1: Philosophy and principles

Category 2: Psychosocial aspects

Category 3: Control of pain and other symptoms

Total FATCOD-B-C score ${ }^{b}$

Subset 1. Attitude toward the interests of dying person

Subset 2. Attitude toward caring for the dying person

Subset 3. Attitude toward the necessity of family support

Subset 4. Attitude toward communication with dying person

Subset 5. Attitude toward fear of caring of dying person

Subset 6 . Attitude toward caring for dying person's families

Abbreviations: PCQN, Palliative Care Quiz for Nursing (Chinese version). FATCOD-B-C, the Frommelt Attitude Toward Care of the Dying scale (Chinese version).

${ }^{a}$ The full list of PCQN questions with all categories can be found in Supplementary table 1.

${ }^{\mathrm{b}}$ The full list of FATCOD-B-C with all subsets can be found in Supplementary table 2.

\section{Nurses' Attitudes Towards Care Of The Dying}

The mean score of the FATCOD-B-C was 103.62 (range 65-145, SD =11.07) (Table 2). We noticed that nurses had a poor attitude in communicating with the dying person. Especially, on question 8, with the majority identifying that they tend to be upset when the dying person is about to give up the hope (Supplementary table 2).

\section{Comparison between propensity score matched cohorts of trained and untrained nurses}

We detected significant imbalances when comparing unmatched data of those attended the JNA training program 2019 and those who were untrained in terms of age, gender, marital status, hospital classification, working years, level of nursing job, working department, oncology nursing specialist, palliative care nursing specialist, experience of caring for dying patients and discussing death with patients or their family members. Following 1:1 propensity score matching, all covariates between both arms were well-balanced (Supplementary table 3). 
In the overall unmatched cohort, the mean total PCQN and FATCOD-B-C scores of the trained nurses were significantly higher than those of untrained nurses. In the matched cohort, the result of PCQN score and FATCOD-B-C score also showed statistically significant differences between trained and untrained nurses. Also, the trained nurses had significantly higher scores on most categories of knowledge and subsets of attitude compared with untrained nurses both in the overall unmatched and matched cohorts. There was only one exception and that was in knowledge of psychosocial and spiritual care between trained and untrained nurses, which disappeared after matching (Table 3). 
Table 3

Knowledge score and attitude score of nurses who attended or did not attend JNA training program 2019 before and after matching

\begin{tabular}{|c|c|c|c|c|c|c|}
\hline & \multicolumn{3}{|c|}{ Before matching } & \multicolumn{3}{|c|}{ After matching } \\
\hline & Trained & $\begin{array}{l}\text { Not } \\
\text { trained }\end{array}$ & $\begin{array}{l}P \\
\text { value }\end{array}$ & Trained & $\begin{array}{l}\text { Not } \\
\text { trained }\end{array}$ & $\begin{array}{l}P \\
\text { value }\end{array}$ \\
\hline No. (\%) of nurses & $\begin{array}{l}1686 \\
(16.78)\end{array}$ & $\begin{array}{l}8362 \\
(83.22)\end{array}$ & & $\begin{array}{l}1483 \\
(50)\end{array}$ & $\begin{array}{l}1483 \\
(50)\end{array}$ & \\
\hline Total PCQN score, mean (SD) & $\begin{array}{l}9.85 \\
(2.52)\end{array}$ & $\begin{array}{l}8.57 \\
(2.79)\end{array}$ & 0.00 & $\begin{array}{l}9.66 \\
(2.51)\end{array}$ & $\begin{array}{l}8.95 \\
(2.64)\end{array}$ & 0.00 \\
\hline $\begin{array}{l}\text { Category } 1 \text {. Philosophy and principles, } \\
\text { mean (SD) }\end{array}$ & $\begin{array}{l}1.51 \\
(0.98)\end{array}$ & $\begin{array}{l}1.15 \\
(0.95)\end{array}$ & 0.00 & $\begin{array}{l}1.47 \\
(0.98)\end{array}$ & $\begin{array}{l}1.25 \\
(0.95)\end{array}$ & 0.00 \\
\hline $\begin{array}{l}\text { Category 2. Psychosocial aspects, mean } \\
\text { (SD) }\end{array}$ & $\begin{array}{l}0.54 \\
(0.69)\end{array}$ & $\begin{array}{l}0.49 \\
(0.66)\end{array}$ & 0.01 & $\begin{array}{l}0.54 \\
(0.69)\end{array}$ & $\begin{array}{l}0.53 \\
(0.65)\end{array}$ & 0.43 \\
\hline $\begin{array}{l}\text { Category 3. Control of pain and other } \\
\text { symptoms, mean (SD) }\end{array}$ & $\begin{array}{l}7.8 \\
(1.99)\end{array}$ & $\begin{array}{l}6.94 \\
(2.22)\end{array}$ & 0.00 & $\begin{array}{l}7.64 \\
(1.97)\end{array}$ & $\begin{array}{l}7.18 \\
(2.07)\end{array}$ & 0.00 \\
\hline Total FATCOD-B-C, mean (SD) & $\begin{array}{l}108.17 \\
(11.81)\end{array}$ & $\begin{array}{l}102.71 \\
(10.68)\end{array}$ & 0.00 & $\begin{array}{l}107.54 \\
(11.59)\end{array}$ & $\begin{array}{l}104.11 \\
(10.91)\end{array}$ & 0.00 \\
\hline $\begin{array}{l}\text { Subset 1. Attitude toward the interests } \\
\text { of the dying person, mean (SD) }\end{array}$ & $\begin{array}{l}23.84 \\
(3.36)\end{array}$ & $\begin{array}{l}22.69 \\
(3.32)\end{array}$ & 0.00 & $\begin{array}{l}23.66 \\
(3.32)\end{array}$ & $\begin{array}{l}23.12 \\
(3.38)\end{array}$ & 0.00 \\
\hline $\begin{array}{l}\text { Subset 2. Attitude toward caring for the } \\
\text { dying person, mean (SD) }\end{array}$ & $\begin{array}{l}22.16 \\
(4.04)\end{array}$ & $\begin{array}{l}20.65 \\
(3.93)\end{array}$ & 0.00 & $\begin{array}{l}22.00 \\
(4.04)\end{array}$ & $\begin{array}{l}20.99 \\
(3.94)\end{array}$ & 0.00 \\
\hline $\begin{array}{l}\text { Subset 3. Attitude toward the necessity } \\
\text { of family support, mean (SD) }\end{array}$ & $\begin{array}{l}21.29 \\
(2.28)\end{array}$ & $\begin{array}{l}20.87 \\
(2.39)\end{array}$ & 0.00 & $\begin{array}{l}21.26 \\
(2.29)\end{array}$ & $\begin{array}{l}21.00 \\
(2.30)\end{array}$ & 0.00 \\
\hline $\begin{array}{l}\text { Subset } 4 \text {. Attitude toward } \\
\text { communication with the dying person, } \\
\text { mean (SD) }\end{array}$ & $\begin{array}{l}13.83 \\
(3.03)\end{array}$ & $\begin{array}{l}13.04 \\
(2.79)\end{array}$ & 0.00 & $\begin{array}{l}13.68 \\
(2.98)\end{array}$ & $\begin{array}{l}13.24 \\
(2.82)\end{array}$ & 0.00 \\
\hline $\begin{array}{l}\text { Subset } 5 \text {. Attitude toward fear of caring } \\
\text { of dying person, mean (SD) }\end{array}$ & $\begin{array}{l}9.91 \\
(2.87)\end{array}$ & $\begin{array}{l}9.18 \\
(2.74)\end{array}$ & 0.00 & $\begin{array}{l}9.87 \\
(2.86)\end{array}$ & $\begin{array}{l}9.29 \\
(2.76)\end{array}$ & 0.00 \\
\hline $\begin{array}{l}\text { Subset 6. Attitude toward caring for the } \\
\text { dying person's families, mean (SD) }\end{array}$ & $\begin{array}{l}17.14 \\
(2.30)\end{array}$ & $\begin{array}{l}16.28 \\
(2.32)\end{array}$ & 0.00 & $\begin{array}{l}17.06 \\
(2.30)\end{array}$ & $\begin{array}{l}16.47 \\
(2.35)\end{array}$ & 0.00 \\
\hline \multicolumn{7}{|c|}{ Abbreviations: JNA, Jiangsu Nursing Association. } \\
\hline Figure titles and legends & & & & & & \\
\hline
\end{tabular}

We further investigated the mean difference of PCQN and FATCOD-C-B in the matched cohort under the groups of categories or subsets item by item. Interestingly, all three items in the category of psychosocial and spiritual care of PCQN showed no difference between trained and untrained nurses while the mean differences of most other items were significantly different between two arms, which favours the improvement of palliative care knowledge of relevant categories (Fig. 2). Four out of five items in the 
subset of questions regarding the attitude toward the necessity of family support on the FATCOD-B-C showed no difference between trained and untrained nurses while the mean differences of most other items were significant between two arms, which favours the improvement of attitude toward relevant subsets (Fig. 3).

\section{Discussion}

This cross-sectional survey recruited over 10,000 registered nurses all over Jiangsu province and revealed that their average level of knowledge and attitudes towards care for the dying were insufficient while those who attended the JNA training program 2019 had significantly better knowledge and attitudes than those who did not. Propensity score matching analysis further showed that a training program may have positive impact on knowledge with learning and attitude gaining a higher score in most categories although it failed to demonstrate improvement in nurses' knowledge in psychosocial and spiritual care or their attitude toward the necessity of family support.

Nurses are frequently exposed to dying patients and their families in their work and lack of knowledge of palliative and hospice care may lead to stress among nurses providing end of life care to those in need (23-25). The average score of PCQN in the present study was 8.79 out of 20 . This score is much lower than that of studies in other countries, such as the UK, the United States, Japan, and South Korea $(26,27)$. This is in agreement with the Quality of Death Index (2015) which indicates that the palliative care in China is still behind most developed countries. Furthermore, our result is lower than that of other similar studies in China (28). A plausible explanation lies in the distribution of participants in different studies. Previous Chinese studies recruited nurses from one or a few departments where palliative care is given frequently while nurses in our study come from all departments of hospitals where they may not often encounter dying patients. In fact, most nurses in our study are from departments other than oncology and geriatrics who may have less access to dying patients. Additionally, our results may also reflect another gap in how Chinese nurses are prepared to work with dying patients. All nurses, regardless which departments they are working at, are expected to understand the palliative care approach from their basic training these days. They are recommended to be exposed to education about palliative care during their initial training in school to understand what palliative care is (29). However, there is a lack of initial preparation of Chinese nursing students as palliative care education and placement in hospice are still missing from our nursing schools. It really should be part of the curriculum by now and perhaps that is something to develop in the future.

Taking a close look at the PCQN results in our study, we found that most nurses seemed to perform better on the knowledge of pain management and other symptoms than on the knowledge of psychosocial and spiritual care or the philosophy and principle of palliative care. This reflects that Chinese nurses tend to pay more attention to patients' physical symptoms while neglect their psychological need and social support for patients and their families as a result of medical education being centered on curative treatment of physical illness (30). The lowest score was on Q5 (It's crucial for family members remain at bedside until death occurs) which only $156(1.6 \%)$ nurses in the study chose correctly. This result is 
similar to most studies conducted in China or in other Asian countries such as Korea. Lost in translation and cultural differences between the West and the East are used to explain this issue well (31) as it is traditional in Asia for family members, especially the son of the patient, to take a last look at the patient before he/she dies to do the filial respect to the patient regardless how difficult it might be.

Participants did report positive attitudes toward caring for the dying person's families. In contrast, the attitude toward communication with the dying person was relatively poor, especially question 8: "I would be upset when the dying person I was caring for gave up hope of getting better," which only scored 1.9. This may reflect a traditional view of death in China that Chinese people are often very afraid of death, as the old saying illustrates, "a living dog is better than a dead lion". This attitude to death has huge impact on people's behaviors when dealing with terminal illness for themselves and for their loved ones. To make it harder, speaking about death and dying is a taboo subject in traditional Chinese culture. It is challenging for nurses to tackle the communication aspects of care of the dying and to keep it culturally relevant and appropriate.

Although the fundamental knowledge and attitudes regarding palliative care among nurses were below expectation, the recently launched JNA training program was successful in improving knowledge and attitudes as the mean differences on examined items favour an improvement of knowledge and attitudes following education. These results were from a well-matched cohort in which most covariates that have impact on their knowledge or attitudes, other than attending the JNA training program, were fully considered and balanced.

The results also revealed some missing facets of curriculum provision of the training program as almost all items on the knowledge of psychosocial and spiritual care and attitude toward the necessity of family support showed no differences between trained and untrained nurses after matching. We reviewed the curriculum of the JNA training program 2019 which contained 18 keynote lectures and 8 onsite visiting and viewing and workshops. Only one lecture involved a topic of psychosocial support with one workshop introducing the model of internet plus for home care and family meeting. Therefore, it is not surprising to find these gaps in the training outcomes.

\section{Limitations}

There are several limitations in the present study. First, we applied a regional-stratified sampling method to make sure that recruited surveys from each region are represented proportionally to the nursing population of Jiangsu province. However, convenient sampling was used within a region as we just collected all valid questionnaires in case there were less than 1000 responses in that region which happened in eight regions. This might explain why most nurses were from tertiary hospitals while only a few were from primary hospitals in this study as city based-nurses are easier to approach via mobile phone app. Second, strictly speaking, the differences of knowledge and attitude between trained and untrained nurses cannot directly attribute to the JNA training program 2019 as this is a cross-sectional study which did not compare the outcomes of trained nurses before and after the training. However, we 
applied a propensity score matching to the cohort to balance other covariates that could have impact on their knowledge or attitude. Therefore, the results strongly implied the effects of the training program.

\section{Conclusions}

This study has generated rich data to help nursing educators identify gaps and areas for improvement in the curricula of the palliative care training programs that are appropriate in oriental socio-cultural contexts. Generally, knowledge of palliative care among Chinese nurses remained insufficient. Traditional training program may improve the general knowledge and attitude while some important facets, such as communication skills, family support, and the psychosocial aspects, are missing. These gaps should be filled in the curricula of future training programs targeting nurses with oriental culture background.

\section{Abbreviations}

FATCOD-B-C: Chinese version of the Frommelt Attitude Toward Care of the Dying scale

JNA: Jiangsu Nursing Association

PCQN: The Palliative Care Quiz for Nursing

PCQN-C: Chinese version of The Palliative Care Quiz for Nursing

\section{Declarations}

\section{Ethics approval and consent to participate}

The research methods were carried in accordance with relevant guidelines and regulations and checked according to the STROBE checklist for cross-sectional research.

The ethical approval was obtained from Jiangsu Nursing Association and the Ethical Committee of the First affiliated hospital of Nanjing Medical University (approval number: 2016-SRFA-076).

All study participants were provided with informed consent electronically prior to participating in the study. The informed consent page presented two options (Yes/No). Only subjects who chose "Yes" were guided to the questionnaire pages, and participants could quit the process at any time.

\section{Consent for publication}

Not applicable

\section{Availability of data and materials}

The datasets generated and/or analysed during the current study are not publicly available due the restriction from the Ethical Committee of the First affiliated hospital of Nanjing Medical University but are 
available from the corresponding author on reasonable request.

\section{Competing interests}

The authors declare that they have no competing interests.

\section{Funding}

This work was supported by the National Science Foundation of China for Young Scholars (Grant No. 71704084)

\section{Authors' contributions}

$\mathrm{XC}$ designed the study and wrote the draft. YZ provided funding support and wrote the draft. AA analyzed and interpreted the data, reviewed and edited the manuscript. XH supervised the study and reviewed the manuscript. JL performed the data analyses and wrote the draft. CS, XW and DW advised and supervised the study and wrote the draft. JW and JD designed the study and interpreted the data and reviewed the manuscript. All authors provided critical comments on drafts of the manuscript and approved the final manuscript.

\section{Acknowledgements}

The authors thank all nurses who responded to the questionnaire and people who distributed the questionnaire to the nurses.

\section{References}

1. Sepúlveda C, Marlin A, Yoshida T, Ullrich A. Palliative Care. Journal of Pain and Symptom Management 2002; 24(2):91-6.

2. Ezer T, Lohman D, Luca GB de. Palliative Care and Human Rights: A Decade of Evolution in Standards. Journal of Pain and Symptom Management 2018; 55(2S):S163-S169.

3. World Health Organization. China country assessment report on ageing and health. World Health Organization; 2015.

4. Economist Intelligence Unit. The 2015 Quality of Death Index: Ranking Palliative Care across the World; 2015. Available from: URL: http://www.economistinsights.com/healthcare/analysis/qualitydeath-index-2015.

5. Ho MK, Hsue CCY, Lai CHN, Chan KT, Cheng CN, Chow CF et al. A cross-sectional study on the attitudes and perceptions of outpatients towards palliative care at the Hong Kong Queen Mary Hospital Hospice Centre. Ann Palliat Med 2020; 9(6):4522-33.

6. Ning XH. Hospice and Palliative Care in Mainland China: History, Current Status and Challenges. Chin Med Sci J 2018; 33(4):199-203. 
7. Ning X. Hospice and palliative care research in mainland China: Current status and future direction. Palliat Med 2019; 33(9):1127-8.

8. Hu K, Feng D. Barriers in palliative care in China. The Lancet 2016; 387(10025):1272.

9. Shen Y, Nilmanat K, Promnoi C. Palliative Care Nursing Competence of Chinese Oncology Nurses and Its Related Factors. J Hosp Palliat Nurs 2019; 21(5):404-11.

10. Xu F, Huang K, Wang Y, Xu Y, Ma L, Cao Y. A Questionnaire Study on the Attitude towards Death of the Nursing Interns in Eight Teaching Hospitals in Jiangsu, China. Biomed Res Int 2019; 2019:3107692.

11. Jiang Q, Lu Y, Ying Y, Zhao H. Attitudes and knowledge of undergraduate nursing students about palliative care: An analysis of influencing factors. Nurse Educ Today 2019; 80:15-21.

12. Wang L, Li C, Zhang Q, Li Y. Clinical nurses' attitudes towards death and caring for dying patients in China. Int J Palliat Nurs 2018; 24(1):33-9.

13. Zheng R-S, Guo Q-H, Dong F-Q, Owens RG. Chinese oncology nurses' experience on caring for dying patients who are on their final days: a qualitative study. Int J Nurs Stud 2015; 52(1):288-96.

14. National Health Commission of China. Inform notice of implementing hospice care practice guideline (trail): National Health Commission of China; 2017 [cited 2021 Feb 21]. Available from: URL: http://www.nhc.gov.cn/cms-search/xxgk/getManuscriptXxgk.htm? id=83797c0261a94781b158dbd76666b717.

15. National Health Commission of China. Notice of Launching the Second Batch of Pilot Work for Hospice Care: National Health Commission of China; 2019 [cited 2021 Feb 21]. Available from: URL: http://www.nhc.gov.cn/lljks/s7785/201912/efe3ed3d9dce4f519bc7bba7997b59d8.shtml.

16. Jiangsu Nursing Association. Notice on Organising the First Training Course for Hospice Care educators in Jiangsu Province: Jiangsu Nursing Association; 2019 [cited 2021 Feb 21]. Available from: URL: http://www.jsna.org.cn/jxjy/2019/10/23154509074.html.

17. Chan CWH, Ng NHY, Chan HYL, Wong MMH, Chow KM. A systematic review of the effects of advance care planning facilitators training programs. BMC Health Serv Res 2019; 19(1):362.

18. Ross MM, McDonald B, McGuinness J. The palliative care quiz for nursing (PCQN): the development of an instrument to measure nurses' knowledge of palliative care. J Adv Nurs 1996; 23(1):126-37.

19. Zou M. Study on status quo of nurses' knowledge and attitudes on palliative care in Shanghai [Master of Science]. The Second Military Medical University; 2007.

20. Adriaansen M, Achterberg T. A test instrument for palliative care. Int J Nurs Stud 2004; 41(1):107-17. Available from: URL: https://pubmed.ncbi.nlm.nih.gov/14670400/.

21. Frommelt $\mathrm{KH}$. The effects of death education on nurses' attitudes toward caring for terminally ill persons and their families. Am J Hosp Palliat Care 1991; 8(5):37-43. Available from: URL: https://pubmed.ncbi.nlm.nih.gov/1742142/.

22. Wang L-P, Li Y-J, Yan W-Z, Li G-M. Development and Psychometric Testing Chinese Version of the Frommelt Attitude Toward Care of the Dying Scale, Form B in Nurses and Nursing Students. J Cancer Educ 2016; 31(1):123-30. 
23. Shepherd J, Waller A, Sanson-Fisher R, Clark K, Ball J. Knowledge of, and participation in, advance care planning: A cross-sectional study of acute and critical care nurses' perceptions. Int J Nurs Stud 2018; 86:74-81.

24. Martins Pereira S, Hernández-Marrero P, Pasman HR, Capelas ML, Larkin P, Francke AL. Nursing education on palliative care across Europe: Results and recommendations from the EAPC Taskforce on preparation for practice in palliative care nursing across the EU based on an online-survey and country reports. Palliat Med 2021; 35(1):130-41.

25. Fristedt S, Grynne A, Melin-Johansson C, Henoch I, Hagelin CL, Browall M. Registered nurses and undergraduate nursing students' attitudes to performing end-of-life care. Nurse Educ Today 2021; 98:104772.

26. Knapp CA, Madden V, Wang H, Kassing K, Curtis C, Sloyer $P$ et al. Paediatric nurses' knowledge of palliative care in Florida: a quantitative study. Int J Palliat Nurs 2009; 15(9):432-9.

27. Smets T, Pivodic L, Piers R, Pasman HRW, Engels Y, Szczerbińska $K$ et al. The palliative care knowledge of nursing home staff: The EU FP7 PACE cross-sectional survey in 322 nursing homes in six European countries. Palliat Med 2018; 32(9):1487-97.

28. Liu Q, Tao J, Gao L, He X, Wang Y, Xia W et al. Attitudes of Front-Line Nurses Toward Hospice Care During the COVID-19 Pandemic. Am J Hosp Palliat Care 2021; 38(2):204-10.

29. Arber A. Student nurses' knowledge of palliative care: evaluating an education module. Int J Palliat Nurs 2001; 7(12):597-603.

30. Li J, Davis MP, Gamier P. Palliative medicine: barriers and developments in mainland China. Current oncology reports 2011;13(4):290-4. Available from: URL: https://pubmed.ncbi.nlm.nih.gov/21487684/.

31. Choi M, Lee J, Kim S-S, Kim D, Kim H. Nurses' knowledge about end-of-life care: where are we? J Contin Educ Nurs 2012; 43(8):379-84.

\section{Figures}




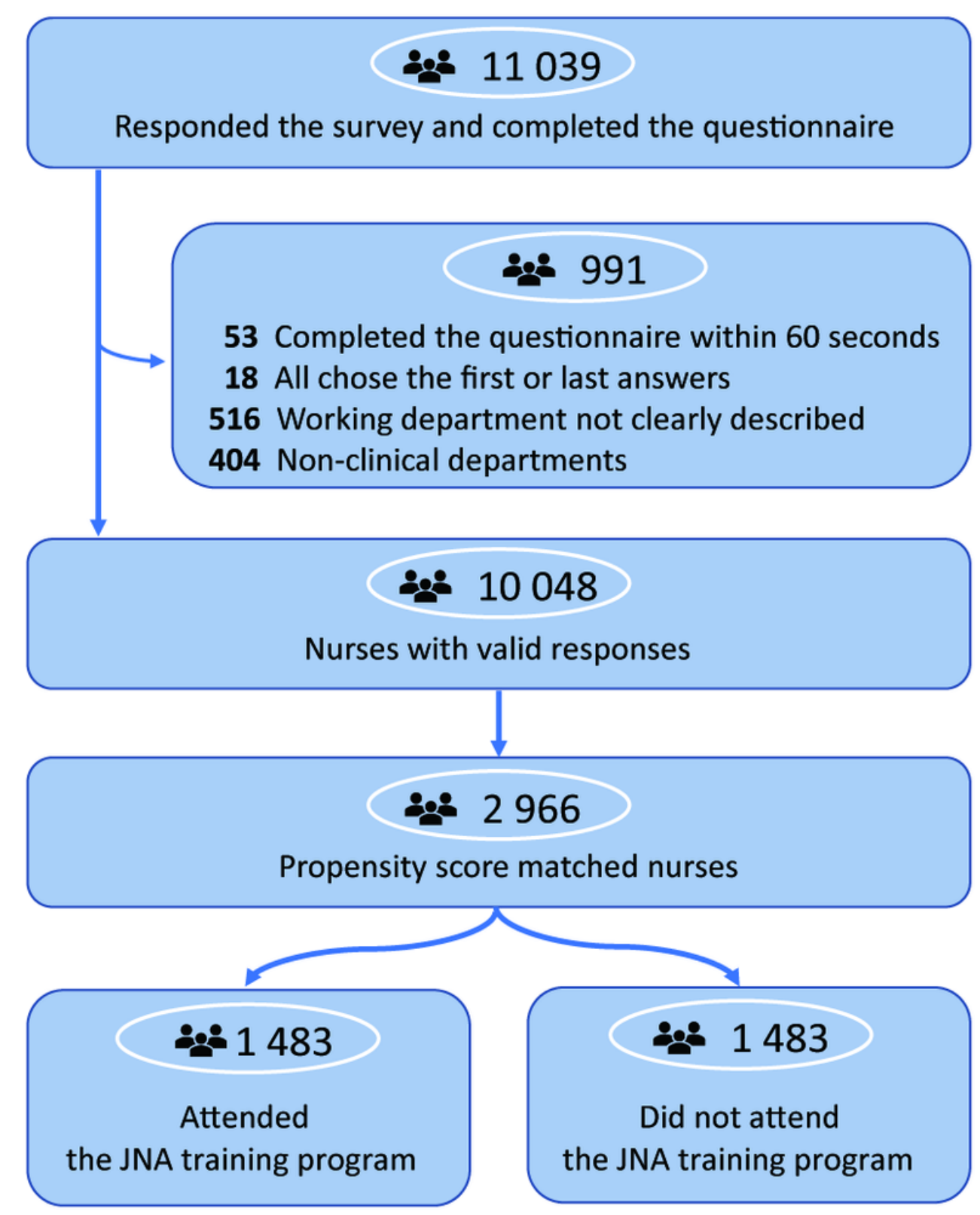

Figure 1

Study flowchart and propensity score matching of participants in the study 
The categories of the Palliative Care Quiz for Nursing (Chinese) Mean differences $(95 \% \mathrm{Cl})$

Category 1. Philosophy and principle of palliative care

Q1. PC is only for downhill trajectory or deterioration

Q9. Provision of $\mathrm{PC}$ requires emotional detachment

Q12. Philosophy of $P C$ is compatible with aggressive treatment

Q17. Accumulation of losses renders burnout inevitable for PC workers

\section{Category 2. Psychosocial and spiritual care}

Q5. It's crucial for family members remain at bedside until death occurs

Q11. Men generally reconcile their grief more quickly than women

Q19. Loss of a contentious one is easier to resolve than intimate one

\section{Category 3. Management of pain and other symptoms}

Q2. Morphine is the standard of other opioids for analgesic effect

Q3. The extent of the disease determines the method of pain treatment

Q4. Adjuvant therapies are important in managing pain

Q6. Electrolyte imbalance associated-drowsiness decreases sedation need

Q7. Drug addiction is a major problem of long-term morphine use

Q8. Individuals who are taking opioids should also follow a bowel regime Q10. drugs with respiratory depression are appropriate for severe dyspnea

Q13. Placebos is appropriate in treatment of some types of pain Q14. High dose codeine causes more nausea and vomiting than morphine

Q15. Suffering and physical pain are synonymous

Q16. Demerol is not an effective analgesic to control chronic pain Q18. Manifestations of chronic pain are different from acute pain Q20. Pain threshold is lowered by anxiety or fatigue

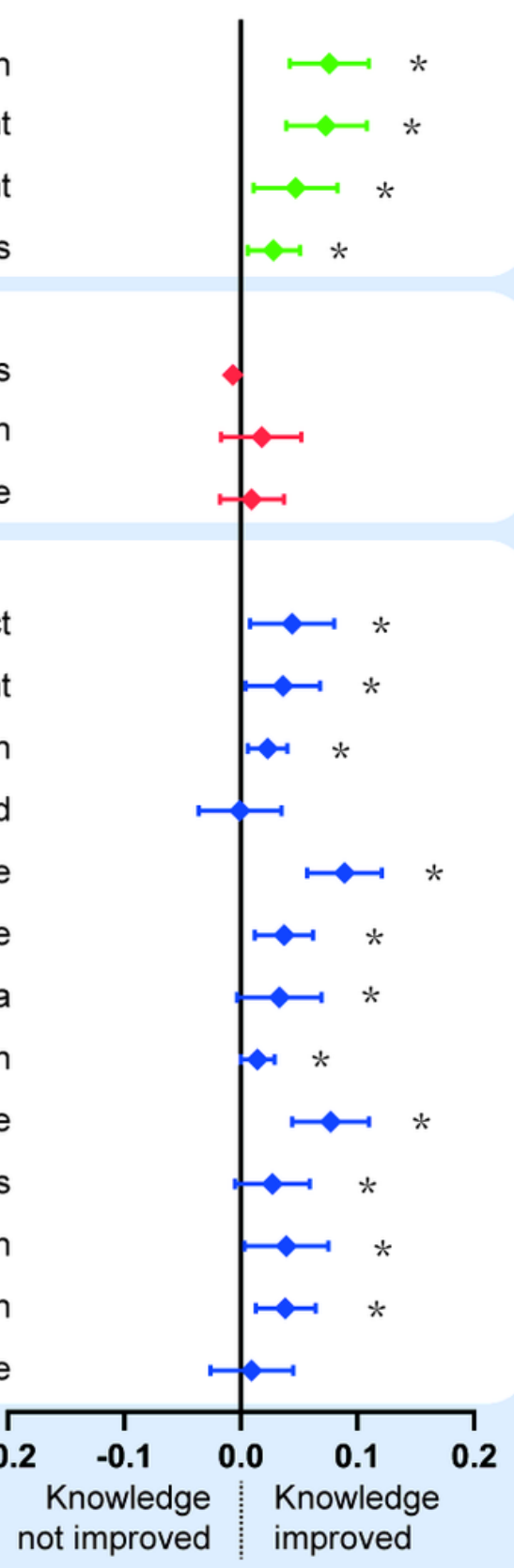

\section{Figure 2}

Mean difference of PCQN score between trained and untrained nurses after propensity score-matching

The questions of PCQN were listed and grouped into three categories with different colors at the left panel. The mean differences of the scores between those who attended the JNA training program and whose who did not attend after propensity score-matching were drawn with colored diamond dots with $95 \%$ confidence interval $(95 \% \mathrm{Cl})$ in line with each question on the right. The mean difference shifting towards right indicates the improvement of knowledge. * $P$ value $<0.05$. JNA, Jiangsu Nursing Association. PCQN, the Palliative Care Quiz for Nursing (Chinese version). 
The subsets of Frommelt Attitude Toward Care of the Dying (Chinese) Mean differences $(95 \% \mathrm{Cl})$

Subset 1. Attitude toward the interests of the dying person

Q19. Dying person should not make decisions about his/her physical care

Q21. It is beneficial for the dying person to verbalize his/her feelings

Q23. Caregivers should permit dying person having flexible visiting

Q24. The dying person and family should be decision makers in charge

Q25. Addiction to painkillers should not be a concern for dying person

Q27. Dying persons should be given honest answers about the condition

Subset 2. Attitude toward caring for the dying person

Q1.Giving care to the dying person is a worthwhile experience

Q2. Death is not the worst thing that can happen to a person

Q5. I would not want to care for a dying person

Q6. The nonfamily caregivers should not talk about death with dying person

Q7. The length of time required to give care to dying person frustrates me

Q13. I would hope the person I'm caring for dies when I am not present

Subset 3. Attitude toward the necessity of family support

Q12. Families should involve in physical care of dying person if they want

Q17. As a patient nears death, the nonfamily caregiver should withdraw

Q18. Families should help the dying one make best of his/her remaining life

Q20. Families should maintain normal environment as possible for dying one

Q29. Families close to dying one often interfere with professional care

Subset 4. Attitude toward communication with dying person

Q3. I would be uncomfortable talking about coming death with dying person

Q8. I would be upset when the dying person gave up hope of getting better

Q11. When patient asks, am I dying? It is best to change to cheerful subject

Q26. I would be uncomfortable if I entered room found dying person crying

Q30. It is possible for nonfamily caregivers help patients prepare for death

Subset 5. Attitude toward fear of caring of dying person

Q9. It is difficult to form a close relationship with the dying person

Q14. I am afraid to become friends with a dying person

Q15. I would feel like running away when the person actually died

Subset 6. Attitude toward caring for dying person's families

Q4. Caring for family should continue throughout grief and bereavement

Q16. Families need emotional support for behavior changes of dying one

Q22. Care should extend to the family of the dying person

Q28. Educating families is not a nonfamily caregiver's responsibility

\begin{tabular}{ccccc}
\hline-0.4 & -0.2 & 0.0 & 0.2 & 0.4 \\
& $\begin{array}{l}\text { Attitude } \\
\text { not improved }\end{array}$ & Attitude & \\
& improved
\end{tabular}

\section{Figure 3}

Mean difference of FATCOD-B-C score between trained and untrained nurses after propensity scorematching

The questions of FATCOD-B-C were listed and grouped into six subsets with different colors at the left panel. The mean differences of the scores between those who attended the JNA training program and 
whose who did not attend after propensity score-matching were drawn with colored diamond dots with $95 \%$ confidence interval $(95 \% \mathrm{Cl})$ in line with each question on the right. The mean difference shifting towards right indicates the improvement of attitude. * $P$ value $<0.05$. JNA, Jiangsu Nursing Association. FATCOD-B-C, Chinese version of the Frommelt Attitude Toward Care of the Dying.

\section{Supplementary Files}

This is a list of supplementary files associated with this preprint. Click to download.

- Tablessupplementary.docx 